\title{
Relações de trabalho, processos cotidianos e empreendimentos de economia solidária: duas experiências do Programa Oportunidade Solidária
}

\author{
Fábio de Oliveira ${ }^{2}$ e Ana Novinsky Leirner ${ }^{3}$ \\ Faculdade de Ciências Humanas e Saúde da Pontifícia Universidade Católica de São Paulo
}

\begin{abstract}
O objetivo da pesquisa foi compreender o desenvolvimento de empreendimentos econômicos solidários tendo como foco de análise as relações cotidianas de trabalho. A pesquisa investigou, através de observações e de quatro entrevistas semi-estruturadas, dois empreendimentos criados por participantes do Programa Oportunidade Solidária da Prefeitura Municipal de São Paulo. A partir do trabalho de campo realizado, foi possível conhecer: o modo de funcionamento de cada empreendimento, sua divisão do trabalho e as principais características das relações cotidianas de trabalho e dos processos de tomada de decisões. Além disso, foi possível reconhecer alguns dos problemas enfrentados por esses empreendimentos e as soluções coletivamente construídas para lidar com eles, como estratégias, práticas e regras singulares.
\end{abstract}

Palavras-chave: Relações cotidianas de trabalho, Cotidiano, Autogestão, Cooperativismo, Políticas públicas.

Work relations, everyday processes, and popular economics enterprises: the Solidarity Opportunity Program experience

The objective of the research was to understand the development of solidarity economics enterprises with the focus on the analysis of everyday work relations. The research investigated, through observations and four semi-structured interviews, two companies supported by Solidarity Opportunity Program, a public policy promoted by Sao Paulo municipal government in 2004. From the fieldwork carried out it was possible to know: the modes of operation of each enterprise, its division of labor and the main features of everyday working relationships and processes of decision-making. Moreover, it was possible to recognize some of the problems faced by these enterprises and the collectively constructed solutions to deal with them, as peculiar strategies, practices and rules.

Keywords: Everyday work relations, Everyday life, Self-management, Cooperativism, Public policies.

\section{Introdução}

D iversos estudos recentes na área de psicologia social têm tomado os empreendimentos de economia solidária ${ }^{4}$ como objeto de análise (Andrada, 2009; Carvalho, 2008; Cortegoso \& Lucas, 2008; Esteves, 2004; Oliveira, 2005, 2007; Sato \& Esteves, 2002; Veronese, 2008; Veronese \& Guareschi, 2005). Essas pesquisas apontam para a importância da investigação detalhada do cotidiano daquelas organizações para que se possa compreender como os trabalhadores constroem estratégias e táticas de auxílio mútuo (Certeau, 1994; Sato \& Oliveira, 2008), de identificação de oportunidades de negócios e de enfrentamento de adversidades econômicas.

\footnotetext{
1 Pesquisa realizada como projeto de Iniciação Científica, com bolsa PIBIC-CEPE da PUC-SP, no ano de 2007.

2 Docente do curso de psicologia da PUC-SP. Psicólogo do Centro de Psicologia Aplicada ao Trabalho do Instituto de Psicologia da Universidade de São Paulo. Responsável pela versão final deste artigo.

3 Psicóloga formada pela PUC-SP. Responsável pela realização das entrevistas, pelas observações e pela redação do relatório de pesquisa.
}

4 A discussão sobre as diferenças entre economia solidária, economia popular e outras denominações podem ser encontradas em Tiriba (2001). 
Considerando as especificidades dos empreendimentos econômicos solidários surgidos no contexto de políticas públicas de geração de renda, o presente estudo justifica-se pelo interesse sobre seu desenvolvimento e suas estratégias de sobrevivência.

Certamente não se pode tributar o desenvolvimento de um empreendimento econômico unicamente às ações de seus membros. Por outro lado, é de grande valia conhecer os modos engenhosos pelos quais os trabalhadores enfrentam as dificuldades impostas pelos contextos materiais em que estão inseridos e, nessa perspectiva, o cotidiano das relações tem grande importância na definição dos rumos tomados pelas iniciativas de trabalho associado (Esteves, 2002).

Além disso, não se pode desconsiderar o papel que desempenha o exercício efetivo da autogestão (Albert, 2004; Castoriadis, 1983) como elemento diferenciador dos empreendimentos solidários em comparação com os regimes heterogeridos das empresas tradicionais (Oliveira, 2005). Aquela forma de gerir - por ser diferente desta última, à qual a maioria dos trabalhadores está acostumada (o taylorismo-fordismo) - traz questionamentos e dúvidas aos trabalhadores, que se veem responsáveis por todos os níveis de funcionamento do empreendimento. Segundo Sato e Esteves (2002), isso é vivido de forma bastante conflitiva no cotidiano, "seja durante o processo produtivo ou deliberativo, seja nas relações interpessoais ou institucionais da cooperativa" (p. 14).

Seguindo por essa via, o objetivo desta pesquisa foi compreender o processo de desenvolvimento de empreendimentos solidários formados a partir de uma política pública de geração de renda, tendo como foco de análise as relações e as práticas cotidianas de trabalho. Nesse sentido, procurou-se levar em conta as dinâmicas existentes nos grupos de trabalho e interrogar: quais são as práticas e as relações estabelecidas entre os sócios e quais suas implicações para o desenvolvimento dessas iniciativas coletivas?

Foram investigados dois empreendimentos formados a partir da iniciativa de participantes do Programa Oportunidade Solidária (descrito em detalhes a seguir): a cooperativa de reciclagem "Sem Fronteiras" e o grupo denominado "Cozinha das Maravilhas", que atua no ramo alimentício. De cada empreendimento foram entrevistados dois sócios ${ }^{5}$, todos estavam envolvidos de algum modo com a gestão de seus empreendimentos. As quatro entrevistas semi-estruturadas abordaram assuntos como o período de incubação, a história do empreendimento, as relações estabelecidas pelos sócios e as formas de tomada de decisões, entre outros. Também foram feitas observações das rotinas de trabalho.

Os documentos, os dados de observação e as conversas com trabalhadores foram analisados buscando-se identificar os diferentes contextos em que se insere cada grupo e os processos cotidianos que materializam os empreendimentos e apreender as condições de produção da ação - o processo de constituição de cada empreendimento, sua relação com as instituições de fomento, as relações com o mercado, o tipo de negócio empreendido etc.

A pesquisa debruçou-se sobre a dimensão psicossocial dos sentidos cotidianos produzidos coletivamente nas relações de trabalho, nas atividades de planejamento e de replanejamento do trabalho, nas negociações cotidianas e nos processos de escolha organizacional (Sato, 1998). Esse enfoque remete à compreensão do trabalho como um processo dialógico-discursivo, isto é, sendo um ordenamento negociado, o trabalho configura-se como processo comunicativo e interativo no qual barganha e argumentação, por exemplo, têm um papel vital (Sato, 2002b; Sato \& Esteves, 2002; Spink, 1996).

5 Cada uma das quatro entrevistas teve duração média de cinquenta minutos. Em três delas foi usado gravador, com a devida permissão dos entrevistados. Todos os entrevistados assinaram termos de consentimento livre e esclarecido. Os nomes utilizados a seguir para designar os entrevistados são fictícios. 


\section{Programa Oportunidade Solidária}

Diante do crescimento do desemprego na década de 90 no Brasil (Singer, 1998, 2000), o poder público, nas diferentes esferas de governo, colocou em prática diversas políticas de geração de emprego e renda em várias regiões do país. No período entre 2001 e 2004, a Prefeitura Municipal de São Paulo, através da Secretaria do Desenvolvimento, Trabalho e Solidariedade (SDTS), colocou em prática um conjunto de ações destinadas ao enfrentamento da pobreza, do desemprego e da desigualdade. Eles consistiam em programas de redistribuição de renda, emancipação econômica e apoio ao desenvolvimento local, independentes entre si, mas atuando de forma integrada (Pochmann, 2004).

O Oportunidade Solidária foi um dos programas de emancipação econômica. Ele estimulava a organização de empreendimentos coletivos (associativos, cooperativos e comunitários) e individuais (micros e pequenos negócios), prioritariamente entre os beneficiários dos programas de redistribuição de renda (Renda Mínima, Começar de Novo, Bolsa-Trabalho e Operação Trabalho). Os bairros abrangidos pelo programa foram definidos segundo o mapa da exclusão (Sposati, 2001), o público alvo do programa eram pessoas que viviam abaixo da linha da pobreza e o planejamento dos empreendimentos visava a economia local.

O Programa Oportunidade Solidária foi concebido inicialmente para durar dez meses, dos quais, os quatro primeiros correspondiam à pré-incubação e os seis seguintes à incubação propriamente dita. O recebimento de bolsa para participação no programa ocorria apenas durante os seis primeiros meses. Permaneceram no programa para o período de incubação os participantes que elaboraram, no período de pré-incubação, projetos de empreendimentos econômicos solidários dos quais desejavam participar como sócios-trabalhadores.

O Programa Oportunidade Solidária foi uma iniciativa na direção de reconhecer as formas de trabalho baseadas nos princípios da economia solidária e responder às suas demandas, criar regulações e mecanismos apropriados levando em conta o potencial de desenvolvimento sócio-econômico que as pessoas pobres possuem. O que não aconteceu sem dificuldades:

As formas de trabalho em autogestão, associativas, solidárias, cooperadas, familiar e outras que escapam ao tradicional emprego ainda são pouco atraentes para uma população que culturalmente foi formada para ter nele o modelo de êxito, de sucesso pessoal (Pochmann, 2003, p. 141).

Nos dois primeiros anos de sua implantação, participaram do programa 15 mil pessoas em 34 distritos do município. Dos inscritos no Oportunidade Solidária, cerca de 4.200 pessoas foram beneficiadas pelos programas redistributivos Começar de Novo e Bolsa-Trabalho. Desses, 3.420 participaram efetivamente dos seis primeiros meses de atividades do Programa Oportunidade Solidária e 1.200 (28,57\%) participaram até o fim. Consolidaram-se 34 empreendimentos associativos e 50 empreendimentos individuais ao final da gestão (Pochmann, 2003).

As principais dificuldades enfrentadas no início da implantação do programa, segundo a avaliação feita por alguns dos formadores, relacionavam-se ao fato de que muitos participantes chegavam às reuniões sem saber exatamente do que se tratavam, tinham sentimentos de incapacidade que dificultavam sua participação e sobrecarregavam os educadores das instituições parceiras com dúvidas de todos os tipos (ITCP PUC-SP, 2003; Pochmann, 2003).

Poucos participantes possuíam recursos financeiros para continuar no programa após o fim da bolsa (em virtude, por exemplo, do custo do transporte) e para investir no 
empreendimento que desejavam constituir, o que diminuiu o número de participantes do programa e impossibilitou que muitos empreendimentos saíssem do papel e realmente gerassem ocupação e renda (Pochmann, 2003).

Segundo Felippe (2004), uma das principais dificuldades dos grupos de bolsistas e exbolsistas era o uso do dinheiro, que, apesar de todo o acompanhamento, era raramente bem administrado. Ela conta também que nos empreendimentos com algum retorno financeiro surgiam outras questões, como o conflito entre sócios (falta de confiança, por exemplo) e, muitas vezes, entre sócios e pessoas que não faziam parte diretamente do grupo (discordâncias entre sócios e seus parentes não-sócios, por exemplo).

O período de pré-incubação tinha como objetivos desenvolver o "espírito empreendedor" e a cultura solidária (capacitando os participante para a autogestão), fortalecer a cidadania e a participação na comunidade local (visando a sustentabilidade econômica, social e ambiental) e o desenvolvimento dos projetos de empreendimentos a serem incubado no momento seguinte, através de um estudo das possibilidades e da viabilidade do projeto proposto, sempre levando-se em consideração o interesse do grupo empreendedor e suas experiências anteriores.

O período de incubação, a partir do qual os participantes já não recebiam mais a bolsa, ao dar continuidade aos trabalhos desenvolvidos na pré-incubação, tinha como objetivos assessorar e amparar os empreendimentos criados na etapa anterior, estimular redes solidárias entre os empreendedores, integrá-los aos agentes locais e criar as bases para o fortalecimento e a viabilidade dos projetos.

Ao final desse processo, como relata Pochmann (2003), notou-se que nem todas as expectativas haviam sido alcançadas e que, apesar de as metodologias utilizadas na incubação terem sido eficientes no que diz respeito ao desenvolvimento pessoal e do cidadão, elas deixaram a desejar nos aspectos relacionados à construção do negócio.

Através de pesquisas feitas durante a implementação do programa (Felippe, 2004; ITCP PUC-SP, 2003), tornou-se claro que os participantes sentiam-se preparados para administrar seus negócios e que suas dificuldades para dar continuidade aos empreendimentos diziam menos respeito aos conhecimentos necessários e mais a aspectos como crédito e financiamento, tecnologias necessárias, garantia de demanda e regulação pública adequada (legislação). Esses fatores muitas vezes impossibilitaram os projetos.

$\mathrm{Na}$ época em que foi feita a avaliação do programa, 83\% dos negócios não geravam quaisquer rendimentos para seus membros e os que o faziam remuneravam cada um com valores entre 50 e 200 reais mensais (Pochmann, 2003). Ainda segundo Pochmann, isso revela a necessidade de um acompanhamento mais longo dos empreendimentos autogestionários, o que também é apontado por Gaiger (2004).

As ações não foram desenvolvidas diretamente pela prefeitura, mas por diversas instituições parceiras. Os dois empreendimentos apresentados a seguir, originários do Programa Oportunidade Solidária, foram assessorados especificamente pela Incubadora Tecnológica de Cooperativas Populares da PUC-SP. A equipe técnica que atuou nesse projeto era composta por graduandos e graduados de diversas áreas (como psicologia, ciências sociais, serviço social e administração).

A estratégia metodológica adotada pela ITCP PUC-SP foi a de iniciar desde o período de pré-incubação a discussão sobre os planos de negócios, como forma de garantir a apropriação do conhecimento sobre como se dá a construção de um empreendimento econômico, independentemente do tipo de negócio escolhido.

A partir dos pré-planos elaborados pelos participantes do programa, constatou-se que, na prática, boa parte das iniciativas reuniam pessoas, familiares ou amigos em atividades como vendas, produção e distribuição, mas muitos desses envolvidos nos projetos não eram bolsistas 
do Programa Oportunidade Solidária, o que foi apontado pelos incubadores como um problema, "pois se inviabiliza um empreendimento em que parte dos associados conhece as bases da economia solidária e do cooperativismo, por exemplo, e os demais não sabem do que se trata e, portanto, não vão aplicar esses conceitos" (ITCP PUC-SP, 2003). Como aponta Spink (2009), nota-se certa dificuldade, por parte dos executores de políticas públicas, de reconhecerem como legítimas as dinâmicas próprias dos negócios de base familiar e de incluírem a compreensão dessas dinâmicas na formulação das próprias políticas.

\section{Cooperativa Sem Fronteiras}

A Sem Fronteiras, fundada em junho de 2004, é uma cooperativa de reciclagem e localiza-se na Zona Norte da cidade de São Paulo. Ela funciona até hoje com o apoio da Prefeitura de São Paulo, que, além de disponibilizar um galpão, empresta também dois caminhões e outros equipamentos.

No início, segundo o tesoureiro, $\operatorname{Marcos}^{6}$, a cooperativa destinava-se a catadores autônomos, mas, segundo os entrevistados, eles não tinham interesse em trabalhar em cooperação formal - "querem ficar fora, nas ruas" - e não tinham a capacidade de "administrar o negócio" como a prefeitura desejava. Aos poucos, os catadores pioneiros (os fundadores) abandonaram a cooperativa e hoje ela funciona com sessenta sócios, dos quais apenas dez estão desde o começo e passaram pela formação em economia solidária e pelo processo de incubação como um todo.

A cooperativa convive com a alta rotatividade de sócios, segundo Marcos : "tem sempre gente nova, amanhã mesmo eu vou pegar um monte de gente". O processo de filiação de novos cooperados é feito pelo tesoureiro, que recolhe os currículos dos interessados, explica o funcionamento da cooperativa, suas regras e, em seguida, os novos cooperados assinam um termo de responsabilidade. Todos os interessados são aceitos, não havendo um processo para a sua seleção, apenas não são admitidos familiares de sócios.

Segundo Paula ${ }^{7}$ no início havia muitas brigas, discussões e vários cooperados chegavam bêbados para trabalhar. Hoje em dia isso não acontece mais, o que eles atribuem à proibição do consumo de bebidas alcoólicas antes ou nos intervalos do trabalho. Outro aspecto apontado pelos cooperados como responsável pela melhoria dessa situação é o "rigor" do novo presidente, que aplica com mais severidade as regras da cooperativa, além de delegar responsabilidades aos cooperados e cobrá-los depois.

Não é porque é uma cooperativa que não tem que obedecer as regras, tem que ter regra, senão todo mundo vai querer mandar. Tem que ter uma pessoa que impõe (...). As pessoas estão mais unidas, porque antes era meio bagunçado, não tinha muito respeito, não tinha horário tão marcado, uma organização que tinha que ter tido e não tinha, mas hoje em dia a responsabilidade é maior para eles, tá funcionando melhor (Paula).

Os resíduos sólidos (oriundos da coleta seletiva) trazidos à cooperativa pela prefeitura passam por diversos processos de separação e o rejeito (parte do material que não pode ser reutilizado) é separado pelos cooperados e levado pela prefeitura até um aterro sanitário. Depois da separação manual em uma esteira, o material é estocado em uma área coberta do lado de fora do galpão e vendido para empresas. A maior parte do processo é feita manualmente e há, ainda, prensa e triturador industriais.

6 Marcos está desde o início na cooperativa e participa da gestão.

7 Paula entrou a menos tempo que Marcos na cooperativa e é uma das coordenadoras das atividades no galpão. 
Além das funções que podem ser desenvolvidas em cada uma dessas etapas, ainda existem as de: limpeza, tesouraria (que também cuida do contato com os clientes), secretaria, coordenação (que organiza o trabalho no galpão, distribuindo as tarefas de acordo com as necessidades da cooperativa), presidência (responsável burocraticamente pela cooperativa e pelas punições), conselho fiscal (responsável também por controlar horários, faltas e atrasos) e conselho administrativo (que colabora com a administração da cooperativa, principalmente nas tomadas de decisões, levando em conta a viabilidade dos projetos).

A divisão diária do trabalho no galpão acontece de acordo com a demanda por trabalhadores em cada posição, apesar de cada um ter sua "posição base", que pode mudar a qualquer momento.

onde dá, a gente tem que ir: aqui é uma cooperativa, tem que fazer aquilo que pedem de você, porque interfere no resto. Não adianta se a menina chegar e falar pra mim que eu tenho que ir pra esteira e eu falar "não, não vou porque não é o meu lugar", tem que ir (Paula).

Já as posições de gestão são ocupadas a partir de eleições que ocorrem de dois em dois anos. Apesar de possuírem tarefas diferentes daquelas da maioria dos cooperados, os " $\mathrm{da}$ diretoria" (assim chamados pelos cooperados) não recebem mais por isso e cumprem os mesmos horários.

Quando questionado sobre a relação entre os cooperados, Marcos lamenta não haver um verdadeiro sentimento de responsabilidade em relação ao próprio trabalho, uma vez que, do ponto de vista do conselho administrativo, muitos cooperados precisam ser cobrados para efetivamente trabalharem.

Paula, que coordena de perto o trabalho, contrapõe-se dizendo que "a maioria trabalha bem", que trabalha honestamente, sem ficar "ganhando nas costas dos outros", porém deixa claro que alguns precisam do conselho fiscal e dos coordenadores "fiscalizando" o trabalho. Além disso, os próprios cooperados acabam vigiando o trabalho uns dos outros, falando muitas vezes diretamente com o colega ou, outras vezes, comentando com o presidente quando alguém está fazendo "corpo mole".

Ela conta que, no início, não achava que iria ficar na cooperativa, mas sua força de vontade e a necessidade falaram mais alto. Hoje em dia diz que não tem vontade de sair porque fez muitas amizades, aprendeu muitas coisas, tem muito carinho pelas pessoas e pelo lugar: "tem um clima muito bom, não tem pressão (...). É um lugar sossegado, tranquilo. Às vezes tem uma coisinha ou outra, mas todo lugar tem".

Ainda segundo ela, as brigas acontecem, mas são eventos passageiros, "coisas bobas" e que hoje em dia o grupo é mais unido, tem mais respeito e amizade.

Na cooperativa, qualquer decisão é tomada em assembleia. Questões como aumento de carga horária, entrada de novos sócios, fofocas etc. também são levadas para esse espaço de decisão coletiva. Paula conta que, no entanto, quando há uma discussão violenta entre cooperados, eles são chamados para conversar com o presidente, que deve então resolver o problema, e, quando duas pessoas "brigam mesmo", ambas são "mandadas embora", decisão que parte do presidente ou do tesoureiro, sem necessariamente haver consulta à assembleia.

As assembleias acontecem mensalmente logo após a entrega da retirada mensal (o "dia do pagamento"), quando são discutidos os assuntos levantados por todos os cooperados ao longo do mês. Além disso, ocorrem, quando necessárias, assembleias extraordinárias para discutir problemas sérios e que precisam ser resolvidos com urgência. Alguns cooperados participam mais das assembleias do que outros, apesar de todos estarem presentes. A maioria dos assuntos levantados pelos cooperados nas assembleias são, segundo Marcos, reclamações do tipo "Fulano chega atrasado, tá brincando demais, não trabalha como eu!". 
Segundo os entrevistados, a incubação contribuiu muito para a manutenção da cooperativa em função da formação recebida. Referem-se aos conhecimentos sobre reciclagem e às discussões sobre o funcionamento de cooperativas e sobre os principais problemas enfrentados por esses empreendimentos (por exemplo, a desconfiança em relação às pessoas que cuidam do caixa, dificuldades de relacionamento entre os cooperados etc.). Hoje, no entanto, a maioria dos cooperados não possui formação em economia solidária e a experiência em uma cooperativa é para eles uma novidade. Assim, muitos dos novos membros não se vêm realmente responsáveis pelo empreendimento e não vêm a conexão direta entre seu trabalho e o faturamento da cooperativa. A novidade do funcionamento autogerido e o modo como a cooperativa apresenta-se a eles levam muitos cooperados a colocarem-se na posição de empregados em vez de posicionarem-se como sócios da cooperativa. Isso fica claro na fala de Paula:

sempre tem que estar em cima porque se não eles não trabalham (...). E se eles não trabalharem eles não ganham (...) ficam batendo papo, (...) não têm consciência que depende de produzir pra ter o dinheiro no final do mês.

Segundo ela, os novos sócios ficam muitas vezes acomodados e, apesar de não serem todos, isso é reforçado pelo fato de que muitos deles estão na cooperativa somente enquanto não se inserem no mercado formal. Isso é sentido pelos entrevistados como se os novos cooperados estivessem lá de passagem, "só pra ganhar dinheiro", o que sugere que algo além do interesse financeiro é esperado dos ingressantes: a aposta na cooperativa como meio de vida a longo prazo.

A partir da fala de Paula a respeito dos motivos que a mantiveram lá, podemos levantar hipóteses sobre o que é esperado dos novos sócios. Segundo a entrevistada, além da necessidade financeira, o que primordialmente a fez permanecer foi sua "força de vontade". Posteriormente, ela aponta como fatores essenciais para a sua permanência na cooperativa: as amizades que fez ao longo dos anos; o carinho que sente pelos outros cooperados e pelo lugar; o fato de ter "aprendido muita coisa" e de o empreendimento tê-la favorecido em tantos outros aspectos da vida.

Busca-se no novo trabalhador uma atitude de sócio do empreendimento, de alguém realmente responsável pelo que acontece na cooperativa, e não a atitude de quem apenas espera - como o funcionário de uma empresa tradicional - receber seu dinheiro no final do mês. Tem-se, então, indicações da existência de uma vivência como sócio que se faz inseparável da vivência como trabalhador (Esteves, 2004) e uma convocação para que cada um assuma esse papel (Oliveira, 2005), o que não garante que ele seja de fato assumido, mas aponta para um processo em curso.

Uma das razões para a sobrevivência da cooperativa Sem Fronteiras parece ser o fato de existir um pequeno núcleo estável de sócios, que permaneceu no empreendimento desde sua formação e é capaz de gerir o negócio. Por outro lado, a existência de uma parcela muito variável de membros que entram e saem do empreendimento demonstra que a cooperativa não tem sido capaz de manter por muito tempo aqueles que chegaram depois de sua fundação, o que aponta para a dificuldade de integrar os novatos ao grupo.

Vigora a regra de que os cooperados infratores são expulsos da cooperativa após três punições (que consistem no impedimento de trabalhar durante um dia e não receber por esse período). Elas são aplicadas após atrasos ou faltas frequentes, excesso de conversas ou de pausas que prejudiquem o trabalho dos outros e problemas sérios de relacionamento com outros cooperados (falta de respeito, agressão física etc.).

A punição já existia como regra na cooperativa, porém não era respeitada. Com a sua efetivação, segundo Paula, os sócios passaram a respeitar os horários, os outros cooperados e a esforçarem-se mais no trabalho. Segundo ela, é como se pensassem: "na próxima suspensão eu 
perco o emprego, e aí como é que faz?". Note-se que o uso da expressão "emprego" (entre outras, pontuadas acima) é uma indicação sutil da ambiguidade entre ser sócio e, ao mesmo tempo, sentir-se como funcionário.

As práticas punitivas estabelecidas refletem a expectativa frustrada em relação à responsabilidade dos cooperados para com o empreendimento. As punições seriam então um artifício para tentar garantir a conduta responsável, mas talvez acabe por manter a constante rotatividade de sócios. Ao final, essa prática acaba por servir como uma espécie de "processo seletivo" dos cooperados entre aqueles que se adéquam ou não ao modo de funcionamento e às expectativas da cooperativa (ou do pequeno grupo estável de sócios).

Segundo os entrevistados, a mudança para uma gestão de estilo mais controlador fez com que, por exigir mais responsabilidade na realização das atividades, os cooperados passassem a sentirem-se, não só responsáveis pelo seu trabalho, mas também pelo funcionamento e pelo desenvolvimento da cooperativa como um todo, o que foi identificado por eles como algo positivo. Segundo Paula, "Agora tá funcionando como cooperativa, as pessoas têm mais respeito, amizade, estão mais unidas", pois, antes de existirem essas regras era "meio bagunçado".

Uma questão importante a ser considerada em relação a essa prática é o fato de que não necessariamente a existência de regras é um resquício do modelo hierárquico das empresas tradicionais. É necessário levar em conta que as regras não foram determinadas por uma instância exterior de poder (Clastres, 2003), mas aceitas em assembleia pelos cooperados e servindo como um instrumento, não de pressão e de exigência de produção (que vêm da subordinação), mas de comprometimento entre os cooperados e com a cooperativa, o que parece ser essencial para sua manutenção.

Ao mesmo tempo, devemos lembrar que o trabalho no galpão é penoso e pode mesmo ser vivido como um verdadeiro fardo por muitos trabalhadores. Assim, inserida em relações relativamente horizontais, a ação de "fazer corpo mole" pode ser interpretada, não só como demonstração de não comprometimento com a com a cooperativa, mas também como uma estratégia de poder possível nesse tipo de relação não-assimétrica. ${ }^{8}$

Outra regra instituída - inexistente nos primórdios e que, ao menos na visão dos cooperados entrevistados, teria colaborado para a melhoria das relações e para a manutenção da cooperativa - é a proibição do ingresso de parentes de sócios. Essa regra foi criada porque muitas vezes as relações familiares dificultavam as relações de trabalho, seja entre os próprios familiares, seja entre um núcleo familiar e os outros cooperados.

O fato de familiares trabalharem juntos, segundo os entrevistados, além de dificultar as outras relações, também trouxe dificuldades para a cooperativa, pois, por cada família constituir-se como um grupo à parte dentro da dinâmica de poder, elas tornavam-se núcleos de pressão, exigindo coisas que muitas vezes iam contra os próprios princípios da cooperativa e, portanto, eram impossíveis de serem aceitas pelos outros cooperados:

Uma vez entrou uma família inteira e era uma força muito grande que eles tinham, "ah, não vamos trabalhar no sábado", entendeu? Era uma força muito grande que tinha, então a gente não pega mais família (Marcos).

Mais um aspecto apontado, no que diz respeito às dificuldades enfrentadas pela cooperativa, é a falta de formação em cooperativismo, que afetaria as relações de trabalho, segundo os entrevistados. Essa opinião torna-se clara na fala de Marcos, que considera como um dos pontos positivos do curso e da incubação oferecidos pelo Programa Oportunidade

8 Devemos lembrar que as relações não-assimétricas ou horizontais não são relações "livres" de poder: elas expressam um contínuo e tenso equilíbrio entre forças que se equivalem, o que exige dos agentes estratégias de poder distintas daquelas utilizadas nas relações assimétricas, diferentes tanto das estratégias dos dominadores, quanto das estratégias de resistência - o "poder do fraco" (Certeau, 1994). 
Solidária, a preocupação dos incubadores em ensinar como se relacionar e como discutir as dificuldades de relacionamento enfrentadas no trabalho associado:

Precisava ter cursos, debates de como se relacionar com os outros cooperados. Entra gente nova na cooperativa que não tem o curso e que não sabem como lidar com os outros. Se nós não tivéssemos os cursos ninguém saberia lidar: é difícil mesmo tendo o curso (Marcos).

Nota-se em suas palavras uma preocupação legítima com o acesso ao conhecimento socialmente produzido, o que inclui compartilhar das discussões e das experiências relacionadas à gestão de empreendimentos solidários. Mas o que impede que os próprios sócios veteranos compartilhem o conhecimento que têm? Além isso, em que medida não há nessa busca por qualificação a pressuposição de que os trabalhadores novatos seriam desprovidos de habilidades para agir inseridos em relações horizontais? Trata-se de uma questão de treinamento (o fetiche da qualificação) ou de necessidade de mudanças nas relações de trabalho estabelecidas na cooperativa que não favorecem outros padrões de ação?

Segundo os sócios entrevistados, uma característica essencial para o funcionamento e a manutenção do grupo é que, por se tratar de uma cooperativa, mesmo os coordenadores e a diretoria (responsáveis mais pelo gerenciamento da cooperativa do que pela execução das atividades de seleção do lixo) não devem impor nada aos outros cooperados, não só nas decisões, mas também na distribuição das atividades. Todos devem pedir, nunca mandar, independentemente das funções exercidas na cooperativa, o que demonstraria a simetria das relações e faz jus, afinal, ao princípio da equidade.

O limite do alcance dessa horizontalidade é apontado por Marcos, quando nos conta que alguns cooperados "têm medo [de expor suas opiniões durante as assembleias], porque acham que vão ser mandados embora": as pessoas comentam ao longo do mês, "vou falar isso ou aquilo", mas na hora da assembleia não falam, às vezes por medo, às vezes por acharem que o assunto já não fazia mais sentido no momento da assembleia. $O$ que acontece mesmo com os reiterados pedidos do presidente da cooperativa, que diz aos cooperados que a participação deles é importante e que "é para isso que serve [a assembleia], para falar o que tá certo e o que tá errado" (Paula).

Isso demonstraria que os cooperados não sentem plenamente ter um espaço para expressar abertamente suas opiniões? Sim, embora, segundo Paula, "quando [os cooperados] não gostam de alguma coisa, chamam no canto e falam [em particular]".

As "conversas de canto" têm o seu papel nos processos cotidianos da autogestão, dos quais os espaços formais são apenas "a ponta do iceberg" (Sato \& Esteves, 2002), mas podem impedir que assuntos importantes sejam discutidos coletivamente nos espaços apropriados quando se tornam a única via de diálogo.

\section{Cozinha das Maravilhas}

A lanchonete Cozinha das Maravilhas é um empreendimento econômico solidário, também fundado em junho de 2004. Ela surgiu a partir da fusão de dois projetos inicialmente distintos de bolsistas do Programa Oportunidade Solidária, que se juntaram pela semelhança de interesses e por serem grupos muito pequenos, o que impediria futuramente a legalização de cada um como cooperativa.

A Cozinha das Maravilhas está localizada na região central da cidade, em um espaço oferecido por um órgão da Prefeitura Municipal de São Paulo. Funciona como a única lanchonete disponível para almoço e lanches no local. 
A maioria dos sócios não se conhecia até o início do programa. Mas descobriram aos poucos que moravam perto uns dos outros, apesar de nunca terem se visto. Isso facilitou a criação de laços de amizade e de companheirismo, que permanecem até hoje entre as atuais sócias e que permitiram que elas escolhessem seus pares entre "quem queria mesmo" levar o projeto adiante.

Diferentemente da cooperativa Sem Fronteiras, todas as atuais sócias são remanescentes do Oportunidade Solidária e participaram dos cursos oferecidos e do processo de incubação.

O empreendimento começou com dez pessoas. Algumas, desse primeiro grupo, saíram por dificuldades de relacionamentos ou por conflitos de opiniões. Hoje elas são cinco sócias. Segundo as entrevistadas, Daniela e Débora, os outros sócios saíram porque não acreditavam no projeto. Elas relataram a dificuldade de encontrar pessoas com quem compartilhassem os mesmos objetivos.

Foi uma opção das próprias sócias não abrir o empreendimento para a participação de pessoas que não haviam participado da incubação ou que tiveram interesse em participar apenas após entrada em funcionamento da lanchonete, pois achavam que essas pessoas só estariam interessadas no dinheiro que conseguiriam (apesar das dificuldades econômicas da lanchonete) e não em trabalhar coletivamente. Isso fica bastante claro na fala de Débora:

Apareceu bastante [gente interessada] (...) só que, quando a gente falava de vir pra reunião as pessoas falavam "ah, não vou perder tempo", "acho que não vou não, vou perder tempo, isso daí não vai dar em nada". Aí, quer dizer, depois que já tá formado... se você não queria nada antes, não vai querer nada depois! De repente quer entrar só pra se encostar no outro! Então, a gente não aceitou.

Como, apesar das fusões de projetos, o número de pessoas trabalhando no empreendimento não alcançou o mínimo necessários para que burocraticamente ele fosse constituído como cooperativa, hoje o grupo tem o status de uma microempresa, apesar de ter funcionamento autogerido e reconhecer-se como um empreendimento econômico solidário. Do mesmo modo, a cooperativa continua como referência:

a cooperativa é uma coisa sem salário, você tem que entrar e participar e o que dá você vai ter, e o povo achou muito difícil porque tinha que ser vinte pessoas, se não nós éramos uma cooperativa [hoje em dia].

As tarefas são divididas de acordo com as habilidades de cada sócia. Daniela, que já sabia cozinhar e que trabalhava com salgados antes de entrar para a lanchonete, fica na cozinha, fazendo e fritando essas iguarias. Débora passa a maior parte do tempo no caixa e Mariana fica no balcão com Carla e Marta. Porém, segundo elas, "à noite todo mundo ajuda a cooperar", cada uma auxiliando no trabalho das outras, independentemente das tarefas prédefinidas, para que todas terminem o trabalho e possam ir embora juntas. Essa troca ou complementação de funções ocorre também durante o dia, quando realizam as tarefas necessárias para o funcionamento da lanchonete, pois todas são capazes de desenvolver as diversas funções, o que também pudemos identificar na Cooperativa Sem Fronteiras.

Segundo Daniela, são ela e Mariana que cuidam da maioria das tarefas burocráticas do empreendimento, como contas a pagar, papéis a serem assinados, relações com a prefeitura. Porém, quando se trata de tomar decisões, não há essa divisão: "o grupo decide, não pode decidir uma pessoa só". Elas sentem que suas opiniões têm peso nas decisões e que são ouvidas e respeitadas pelo grupo. Segundo elas, quando há algum problema a ser resolvido, todas se reúnem para conversar, levantar opiniões e decidir a melhor atitude a ser tomada: "se surgir um 
probleminha naquele momento, digamos de manhã, a noite a gente vai conversar. Às vezes sai um pouquinho das estribeiras, mas ai a gente fala 'não, a noite a gente conversa'".

O principal tipo de discussão que acontece na Cozinha das Maravilhas é sobre como as atividades deveriam ser realizadas, pois muitas vezes uma sócia tem um jeito de fazer as coisas com o qual nem todas concordam. Dizem que muitas vezes falam umas às outras: "não faz assim que não dá certo, faz do outro jeito", mas dizem que as opiniões desse tipo nem sempre são ouvidas.

Assim, se as dificuldades econômicas e as de encontrar pessoas que compartilhassem com elas os mesmos objetivos foram mencionadas, também foram apontadas outras coisas que dificultam o funcionamento do empreendimento, como os conflitos, as diferenças de opinião e o desrespeito ao que foi combinado nas reuniões: "Bom, às vezes já teve reunião em que a gente não chegou a acordo nenhum, sobre os horários de trabalho, então [depois] foi feito o acordo e depois voltaram [a fazer o que era feito antes]" (Daniela).

Hoje, no entanto, sentem que confiam mais umas nas outras, porque em um grupo menor é possível conhecer melhor as pessoas e, além disso, com o passar do tempo, as sócias "já tomaram juízo", isto é, já compreenderam o que é estar em um empreendimento no qual todos são sócios, o que é visto como um fator de sobrevivência da lanchonete.

Como parte da confiança existente entre elas e da consciência de ser membro de um empreendimento coletivo, a possibilidade de adequar o tempo do trabalho ao tempo da vida fora do trabalho é apontado como uma importante diferença em relação à condição de funcionárias: "[Por exemplo], o pai da Mariana tá doente e precisa levar ele no médico, então, precisa faltar, precisa cuidar do pai. Tem que apoiar nas horas boas e nas horas difíceis para ir pra frente" (Débora). No cruzamento de interesses de diferentes esferas da existência que envolvem os processos decisórios, a horizontalidade das relações permite que interesses de ordem pessoal participem da conversa (Sato, 2002a).

Ainda sobre as estratégias de sobrevivência, podemos compreender a decisão pela não formalização em cooperativa como um modo de contornar a falta de envolvimento dos sócios com o empreendimento - como observado na cooperativa Sem Fronteiras. Abrindo mão de oficializar-se (contrariando as expectativas dos incubadores) e insistindo em ser um grupo pequeno, a Cozinha das Maravilhas preveniu-se desse problema, uma vez que, mantendo o núcleo original, garantiu que todas as sócias estivessem de fato envolvidas com o trabalho e com o grupo, além de estarem todas habituadas ao trabalho coletivo.

Deve-se considerar o caráter negativo da aposta em um modelo ideal de empreendimento - tanto em uma "cooperativa ideal", quanto na ideia da cooperativa como "o empreendimento ideal". Refletindo os pequenos empreendimentos de cunho doméstico (Spink, 2009), as sócias da Cozinha das Maravilhas apostaram em um grupo pequeno não formalizado como cooperativa em função dos laços fortes estabelecidos entre elas.

Isso, em comparação com a cooperativa Sem Fronteiras - que proibiu familiares de associarem-se, pelos problemas que causavam -, permite levantar uma questão interessante: até que ponto o envolvimento entre os sócios para além das relações formais de trabalho pode ajudar o empreendimento a atingir uma maior coesão do grupo ou pode prejudicá-lo quando os sócios se fragmentam em subgrupos rivais?

Neste caso, o número restrito de integrantes permitiu ao empreendimento um maior envolvimento entre as sócias, de um modo positivo, e também fez com que surgissem outras formas de resolução de problemas cotidianos. Como já dissemos, não há assembleias regulares, elas são convocadas sempre que as sócias sentem que são necessárias. Essa foi uma solução eficaz, pois, segundo Daniela, não ficam "pendências" em relação a algo que tenha acontecido no mesmo dia. 
Segundo ela, cada uma sabe o que tem que fazer: cada uma faz sua parte e tem isso sob controle, o que era uma dificuldade no início, pois umas tinham experiência e outras não e "aí [o sócio que não tem experiência] acha que o outro quer mandar". Como algumas das sócias já estavam no ramo alimentício quando o grupo foi formado, elas costumavam explicar como as coisas deveriam ser feitas e pedir para que as sócias sem conhecimentos anteriores na área fizessem como era indicado. Esse "pedir" (talvez por denunciar a disparidade de conhecimento técnico) era muitas vezes compreendido como "mandar". O conflito foi resolvido com o tempo, a partir do momento em que o conhecimento técnico entre elas, tanto na cozinha, quanto na rotina administrativa, foi igualando-se. As questões em relação aos conflitos ligados ao "mandar" e ao "pedir" aparecem, ainda, nas exigências do tom adequado ao falar: "às vezes as pessoas falam mais alto, mas não têm jeito pra falar e a gente não tá lá pra ouvir isso".

Do mesmo modo como observado por Oliveira (2007), "pode ser reconhecido um forte sentimento de repúdio à subordinação" (p. 80) nesse tipo de conflito. Há uma percepção clara de a quem se deve obedecer e de quem não se deve receber ordens. Mesmo a autoridade daquele que porta um saber especializado deve deixar claro que uma sugestão não é uma ordem. Afinal, na autogestão, o especialista oferece informações para a tomada de decisão, não é ele sozinho que decidirá o caminho a seguir (Albert, 2004).

\section{Considerações finais}

Apesar de os empreendimentos estudados terem seguido trajetórias distintas após a incubação, pudemos reconhecer elementos que possibilitaram compreender as relações estabelecidas entre os membros de cada uma dos grupos estudados, considerando as peculiaridades dos ramos de atividades, os processos decisórios, as formas de gestão implementadas em cada local e os modos de compreensão da realidade construídos coletivamente.

As especificidades do trabalho de reciclagem (o ganho de escala, por exemplo) exigem da cooperativa Sem Fronteiras a manutenção de um certo contingente de trabalhadores, bem maior do que o mínimo exigido de vinte sócios para a formação de uma cooperativa. Seus dez membros fundadores remanescente não poderiam, por exemplo, ter tomado a mesma decisão que as cinco sócias da lanchonete Cozinha das Maravilhas, que, por sua vez, pela natureza da atividade, não demanda um número muito grande de trabalhadores. A natureza de cada um dos empreendimentos apresenta desafios cotidianos diferentes para seus respectivos sócios.

A lanchonete encontrou na coesão e na confiança entre as sócias a chave de sua sobrevivência, fechando as portas para novos membros. $O$ galpão de reciclagem, ao não conseguir manter seus sócios - em função das características da população da qual se originam seus membros, da baixa remuneração, da penosidade do trabalho e do tipo de interesse que leva os catadores a associarem-se -, teve que enfrentar os problemas ligados à alta rotatividade de trabalhadores e à integração dos novatos: as punições e as ameaças de expulsão (previstas em estatuto e decididas por assembleia) entraram como formas de garantir o empenho e a dedicação dos membros. 


\section{Referências}

Albert, M. (2004). Buscando a autogestão. In M. Albert, N. Chomsky, P. Ortellado, M. Bookchin \& A. Guillén (Orgs.), Autogestão hoje: teorias e práticas contemporâneas (pp. 17-41). São Paulo: Faísca Publicações Libertárias.

Andrada, C. F. (2009). Encontro da política com o trabalho: um estudo psicossocial sobre a autogestão das trabalhadoras da Univens. Porto Alegre: Abrapso Sul.

Carvalho, A. M. R. (2008). Cooperativa de catadores de materiais recicláveis de Assis - Coocassis: espaço de trabalho e de sociabilidade e seus desdobramentos na consciência. Tese de Doutorado, Instituto de Psicologia, Universidade de São Paulo, São Paulo.

Castoriadis, C. (1983). Autogestão e hierarquia. In Socialismo ou barbárie: o conteúdo do socialismo (pp. 211-226). São Paulo: Brasiliense.

Certeau, M. (1994). A invenção do cotidiano: artes do fazer. Petrópolis: Vozes.

Clastres, P. (2003). A sociedade contra o Estado: pesquisas de antropologia política. São Paulo: Cosac Naify.

Cortegoso, A. L. \& Lucas, M. G. (2008). Psicologia e economia solidária: interfaces e perspectivas. São Paulo: Casa do Psicólogo.

Esteves, E. G. (2002). Emprego versus trabalho associado: despotismo e política na atividade humana de trabalho, Cadernos de Psicologia Social do Trabalho, 5, 51-56.

Esteves, E. G. (2004). Sócio, trabalhador, pessoa: negociações de entendimentos na construção cotidiana da autogestão de uma cooperativa industrial. Dissertação de Mestrado, Instituto de Psicologia, Universidade de São Paulo, São Paulo.

Felippe, C. A. (2004), O Cooperativismo como uma alternativa de geração de trabalho e renda. Trabalho de Conclusão de Curso, Faculdade de Ciências Sociais, Pontifícia Universidade Católica de São Paulo, São Paulo.

Gaiger, L. I. (2004). Sentidos e experiências da economia solidária no Brasil. Porto Alegre: UFRGS.

ITCP PUC-SP (2003). Relatório de Pré-Incubação. [mímeo]

Oliveira, F. (2005). Relações de trabalho e sentidos do cooperativismo. Tese de Doutorado, Faculdade de Psicologia, Pontifícia Universidade Católica de São Paulo, São Paulo.

Oliveira, F. (2007). Os sentidos do cooperativismo de trabalho: as cooperativas de mão-de-obra à luz da vivência dos trabalhadores. Psicologia $\mathbb{E}$ Sociedade, 19 (especial 1), 75-83.

Pochmann, M. (2004). Desenvolvimento econômico e inclusão social. In Reestruturação produtiva: perspectivas de desenvolvimento local com inclusão social. Petrópolis: Vozes.

Pochmann, M. (Org.). (2003). Outra cidade é possível: alternativas de inclusão social em São Paulo. São Paulo: Cortez.

Sato, L. (1998). Astúcia e ambiguidade: as condições simbólicas para o replanejamento negociado do trabalho no chão de fábrica. Tese de Doutorado, Instituto de Psicologia, Universidade de São Paulo, São Paulo.

Sato, L. (2002a). Prevenção de agravos à saúde do trabalhador: replanejando o trabalho através das negociações cotidianas. Cadernos de Saúde Pública, 18 (5), 1147-1166.

Sato, L. (2002b). Replanejamento do trabalho como construção e negociação de significados. In L. H. Borges, M. G. Moulin \& M. D. Araujo (Orgs.), Organização do trabalho e saúde (pp. 71-85). Vitória: EDUFES.

Sato, L. \& Esteves, E. G. (2002). Autogestão: possibilidades e ambiguidades de um processo organizativo peculiar. São Paulo: ADS-CUT.

Sato, L. \& Oliveira, F. (2008). Compreender a gestão a partir do cotidiano de trabalho. Aletheia, 27 (1), 188-197.

Singer, P. (1998). Uma solução não capitalista para o desemprego. In Globalização e desemprego: diagnóstico e alternativas (pp. 118-125). São Paulo: Contexto.

Singer, P. (2000). Globalização, precarização do trabalho e exclusão social. In Globalização e desemprego: diagnósticos e alternativas. São Paulo: Contexto.

Spink, P. K. (1996). A organização como fenômeno psicossocial: notas para uma redefinição da psicologia do trabalho. Psicologia $\mathbb{E}$ Sociedade, 8 (1), 174-192.

Spink, P. K. (2009). Micro cadeias produtivas e a nanoeconomia: repensando o trabalho decente. Cadernos de Psicologia Social do Trabalho, 12 (2), 227-241. 
Sposati, A. (2001). Mapa da exclusão/inclusão social da cidade de São Paulo. São Paulo: Educ.

Tiriba, L. (2001). Economia popular e cultura do trabalho: pedagogia(s) da produção associada. Ijuí, RS: Unijuí.

Veronese, M. V. (2008). Psicologia social e economia solidária. Aparecida: Ideias \& Letras.

Veronese, M. V. \& Guareschi, P. (2005). Possibilidades emancipatórias e solidárias do trabalho: campo fértil para a prática da psicologia social crítica. Psicologia $\mathbb{E}$ Sociedade, 17 (2), 58-69.

\section{Endereço para correspondência}

faboli@uol.com.br, ana.leirner@gmail.com

Recebido em: 02/09/2008

Revisado em: 06/10/2009

Aprovado em: 13/10/2009 